Supporting Information

\title{
Production of 7-epi-Pectenotoxin-2 Seco Acid and Assessment of its Acute Toxicity to Mice
}

Christopher O. Miles, Alistair L. Wilkins, John S. Munday, Rex Munday, Allan D. Hawkes, Dwayne J. Jensen, Janine M. Cooney, and Veronica Beuzenberg

${ }^{1} \mathrm{H},{ }^{13} \mathrm{C}, \mathrm{DEPT}, \mathrm{COSY}, \mathrm{TOCSY}, \mathrm{HSQC}$ and HMBC NMR spectra (6 pages) 
${ }^{1} \mathrm{H}$ NMR spectrum $\left(\mathrm{CD}_{3} \mathrm{OD}\right), 0.8-3.0 \mathrm{ppm}$ region

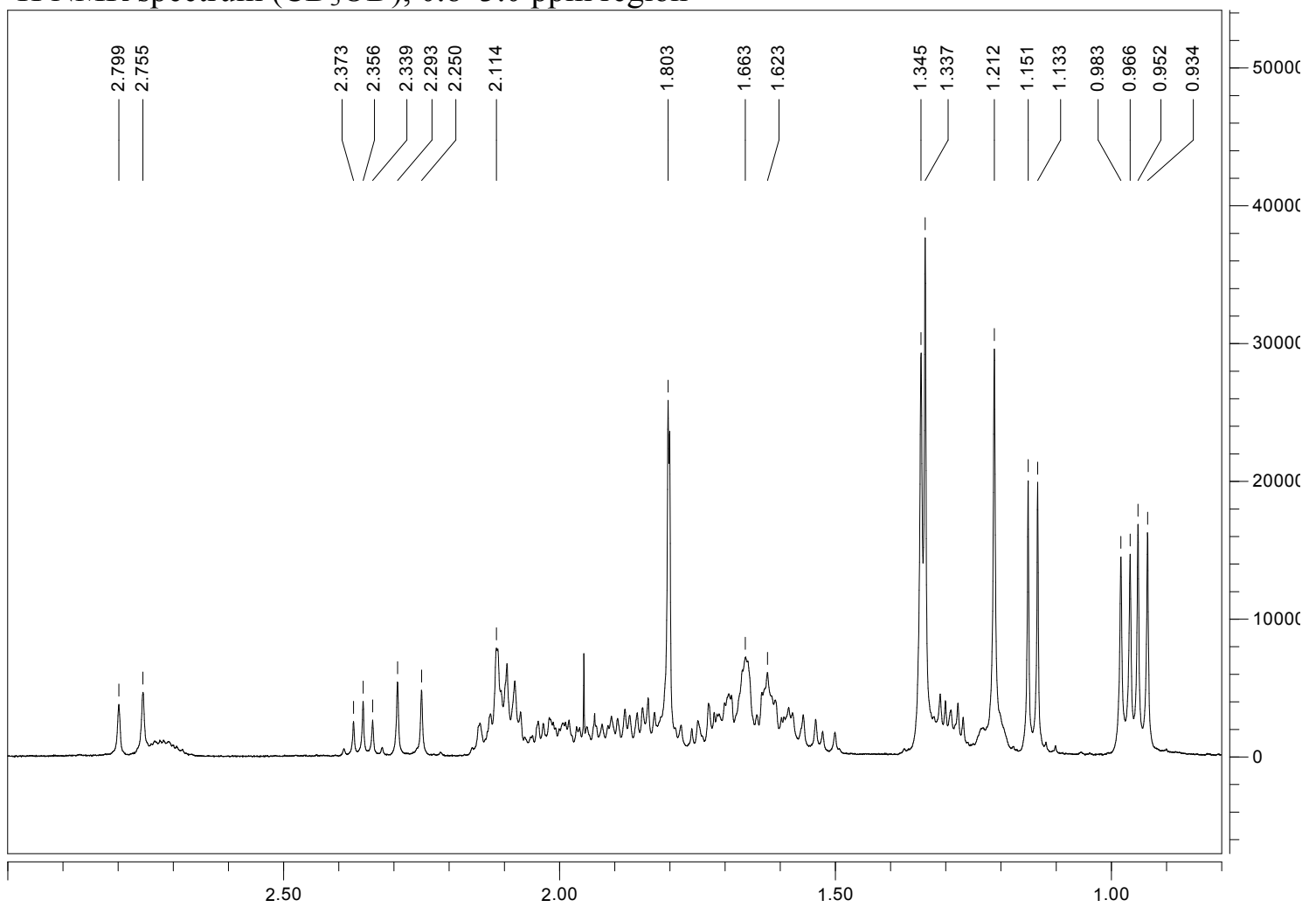

ppm (t1)

${ }^{13} \mathrm{C}$ NMR spectrum $\left(\mathrm{CD}_{3} \mathrm{OD}\right), 90-230 \mathrm{ppm}$ region

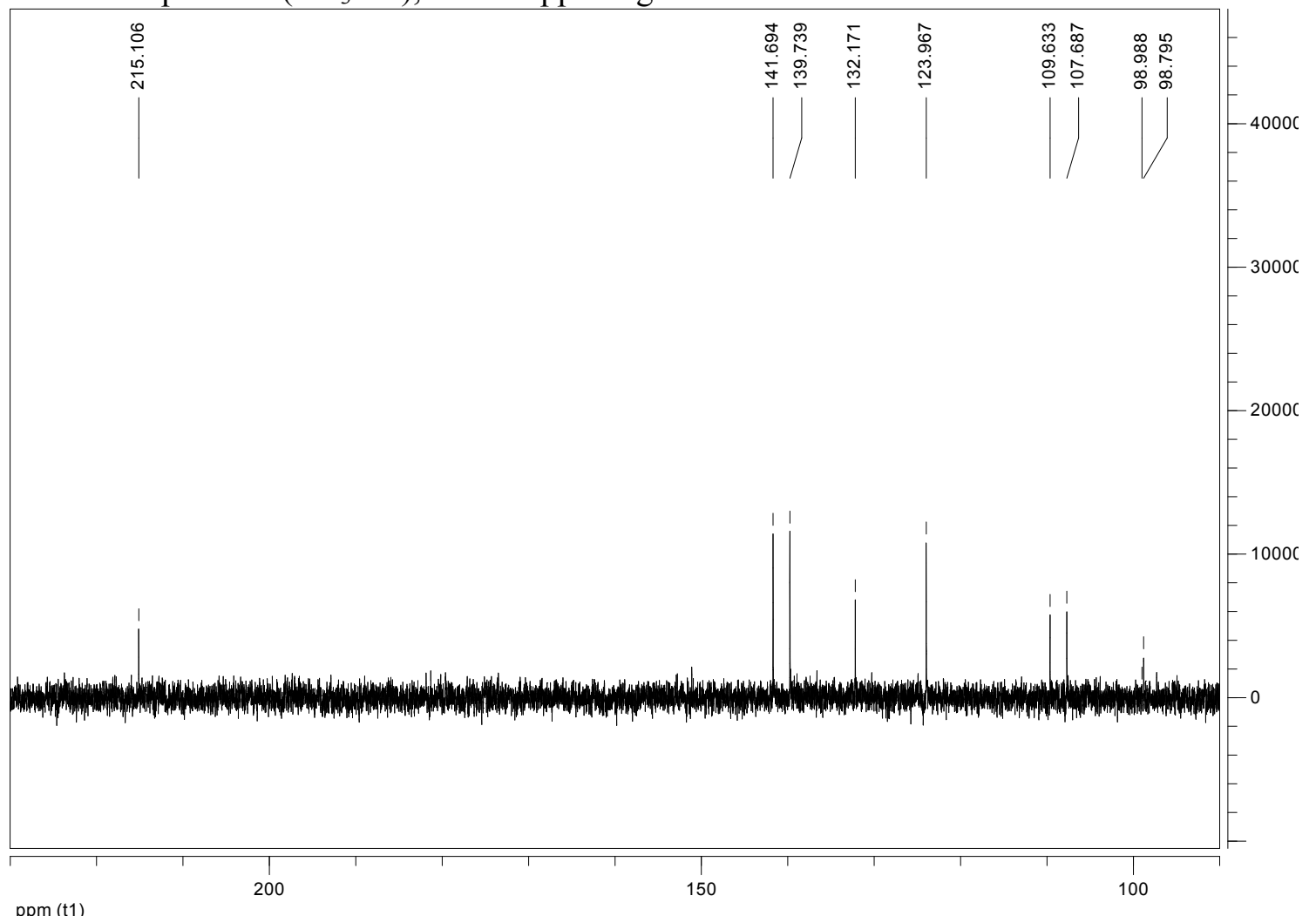



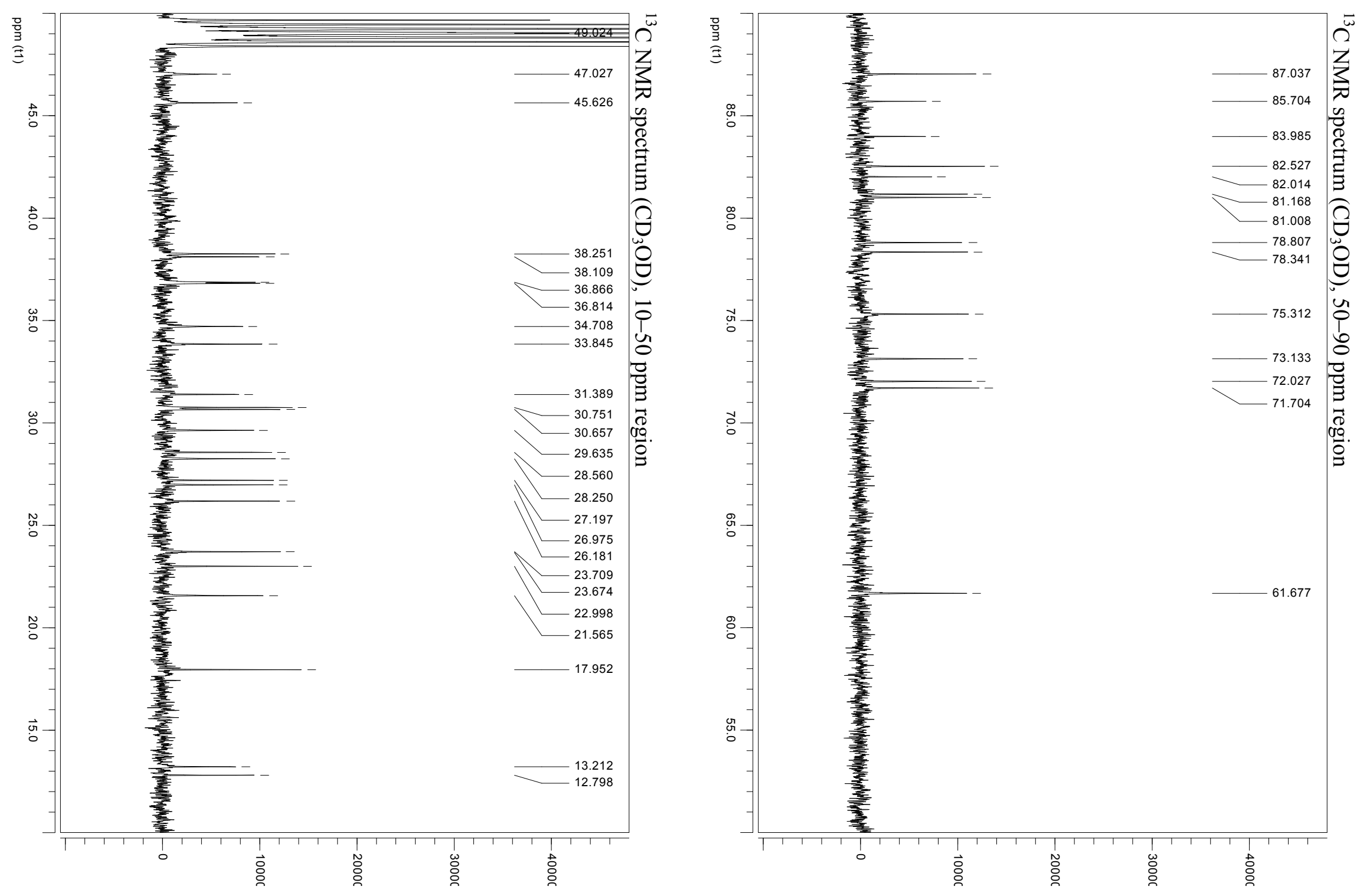

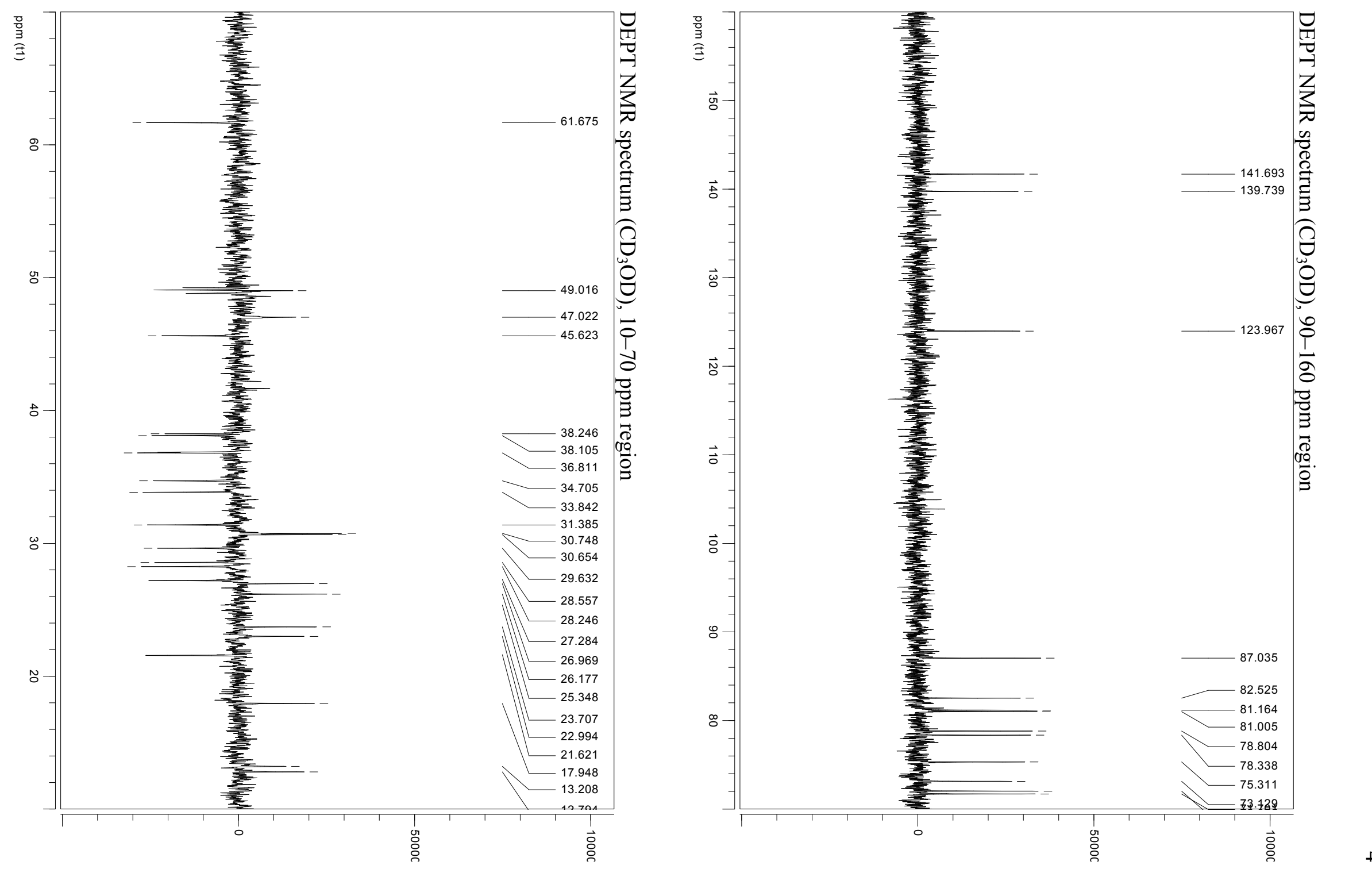
COSY NMR spectrum $\left(\mathrm{CD}_{3} \mathrm{OD}\right)$

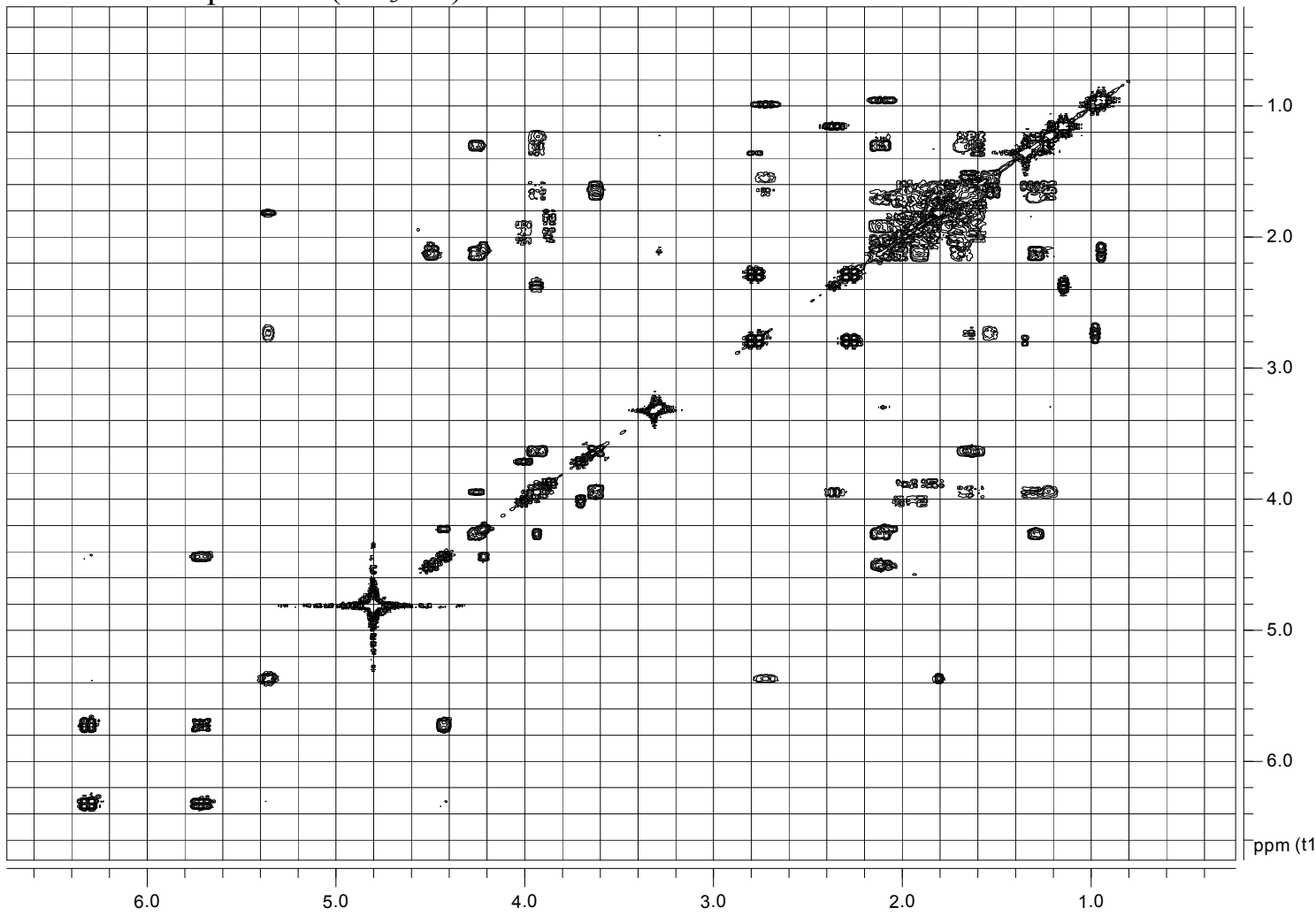

ppm (t2)

TOCSY NMR spectrum $\left(\mathrm{CD}_{3} \mathrm{OD}\right)$

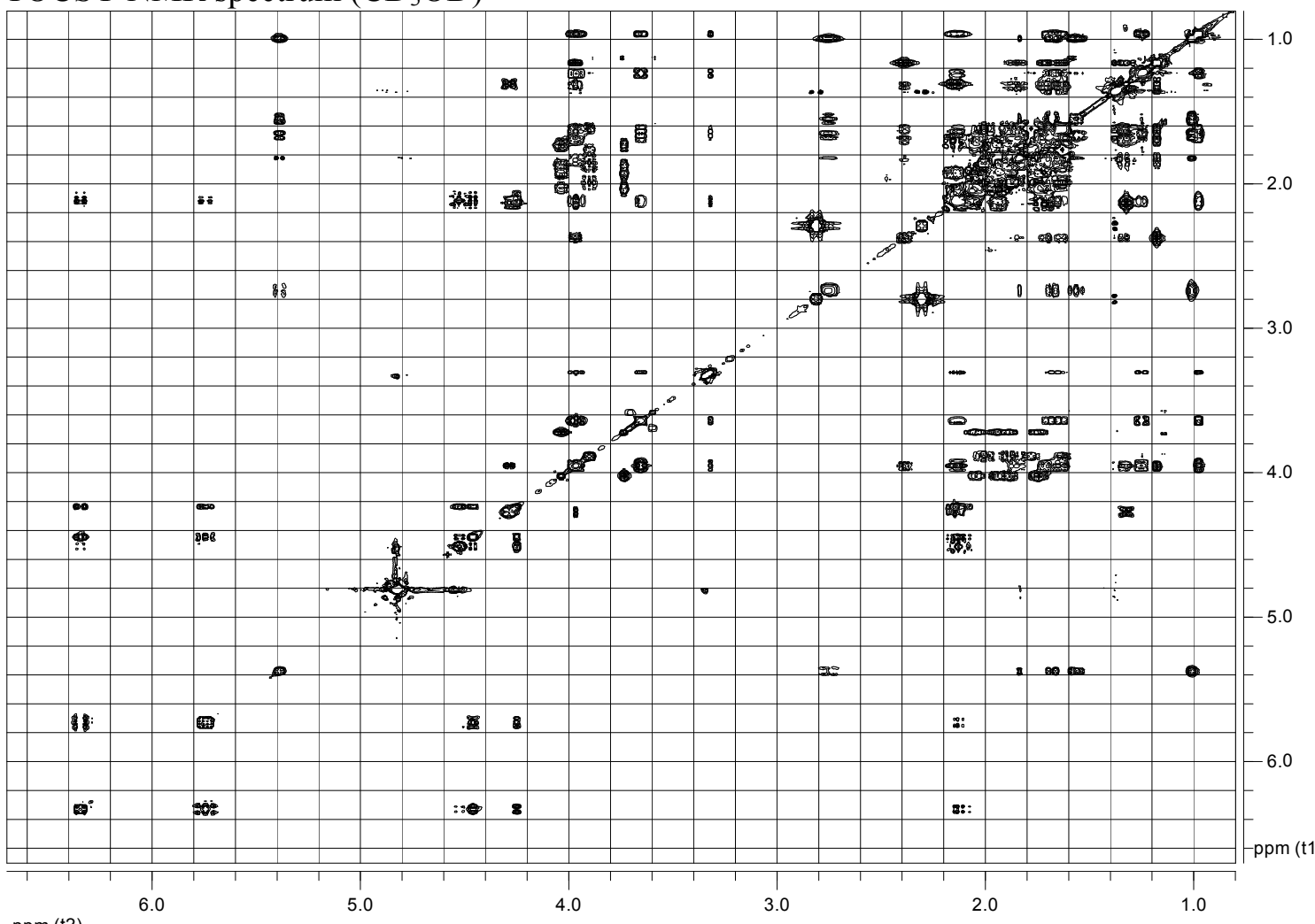


HSQC NMR spectrum $\left(\mathrm{CD}_{3} \mathrm{OD}\right)$

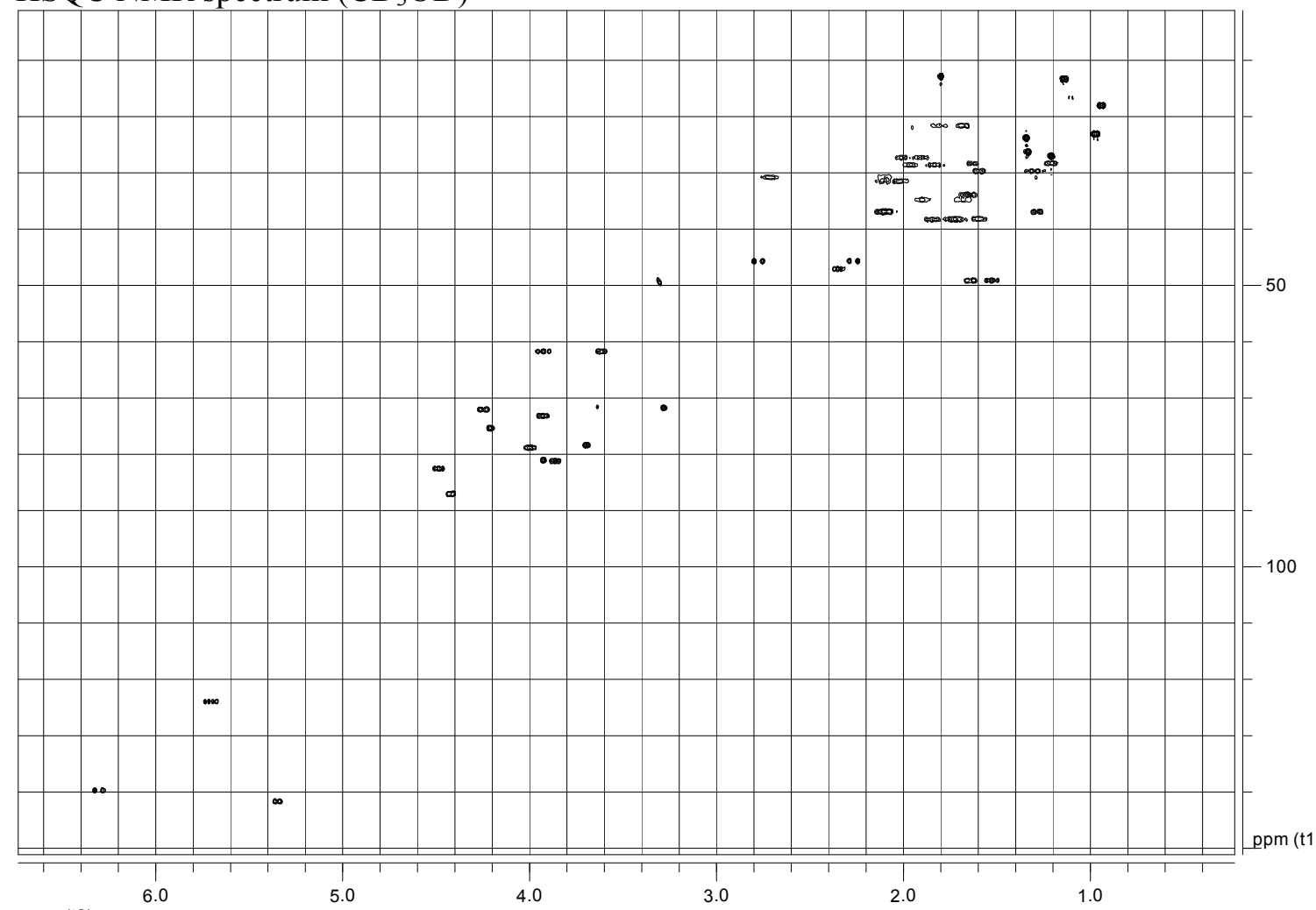

ppm (t2)

HMBC NMR spectrum $\left(\mathrm{CD}_{3} \mathrm{OD}\right), 0.8-2.0 / 10-200 \mathrm{ppm}$ region

\begin{tabular}{|l|l|l|l|l|l|l|l|l|l||}
\hline & & & & & & & & & \\
\hline & & & & & & & & & \\
\hline \\
\hline
\end{tabular}

